\title{
Desalination and Aquifer Storage and Recovery Potential of the Saline Edwards Aquifer, Central Texas
}

\author{
Brian A. Smith, Ph.D., PG \\ Brian B. Hunt, PG
}

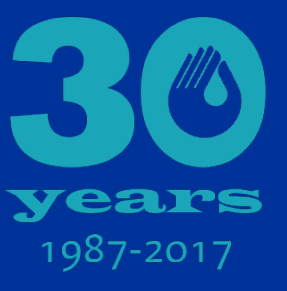

South Central GSA

March 13, 2017 


\section{Edwards Aquifer}

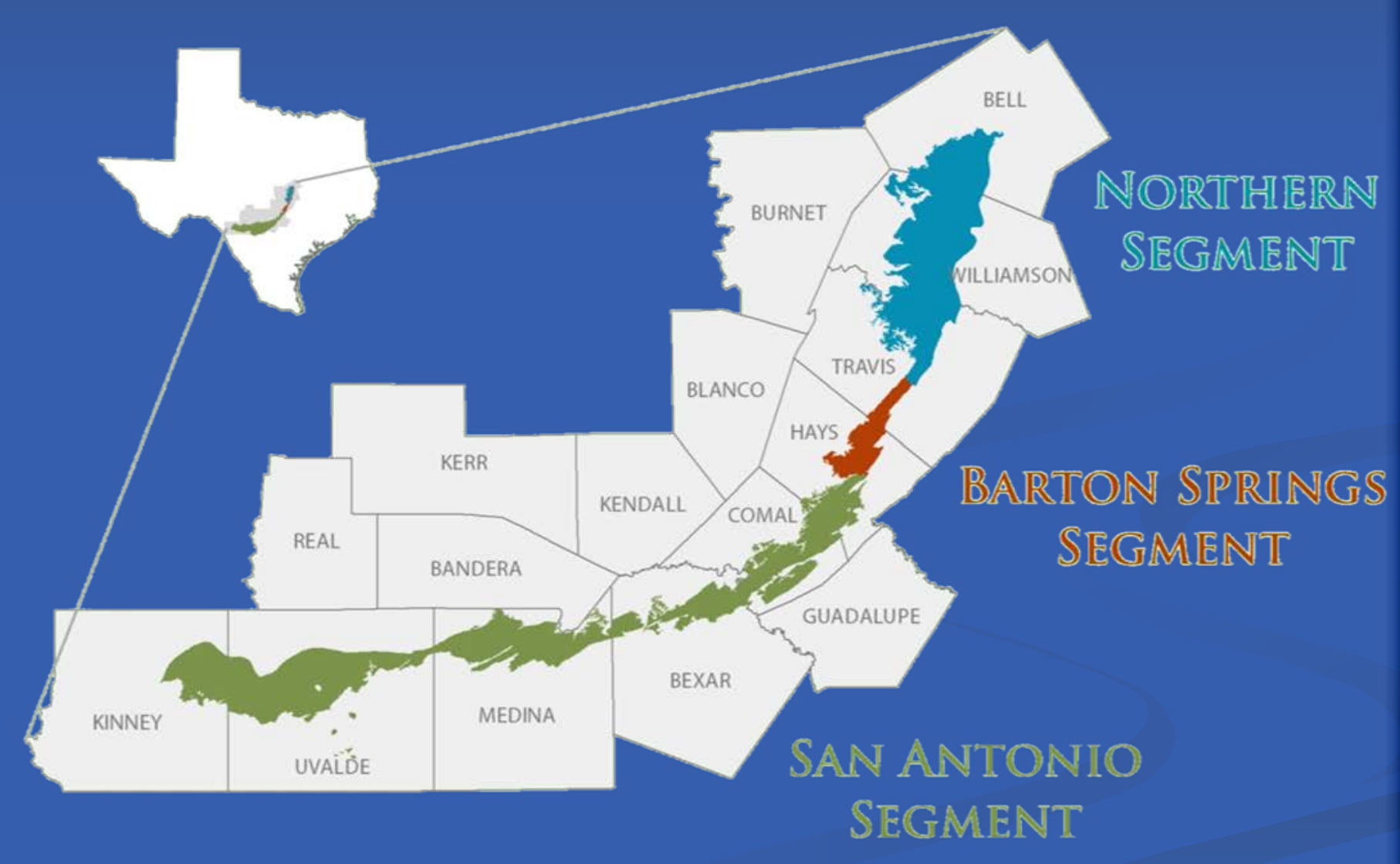

Barton Springs 


\section{Previous Saline-Interface Studies}

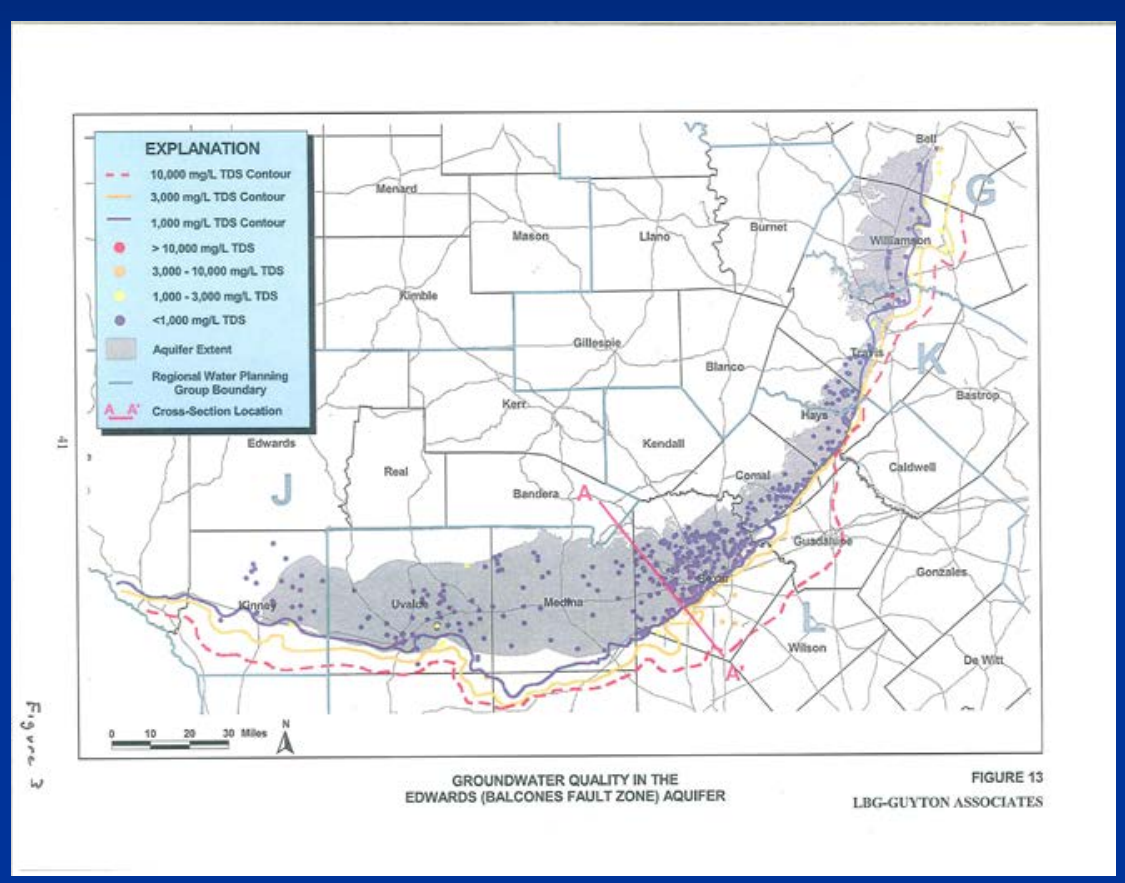

- TWDB (Flores 1990)

- EUWD (Poteet 1992; Schultz)

- SAWS

- USGS (Thomas/Lambert etc.)

- EAA

- UT Austin (Oetting, Banner and Sharp, 1995) 


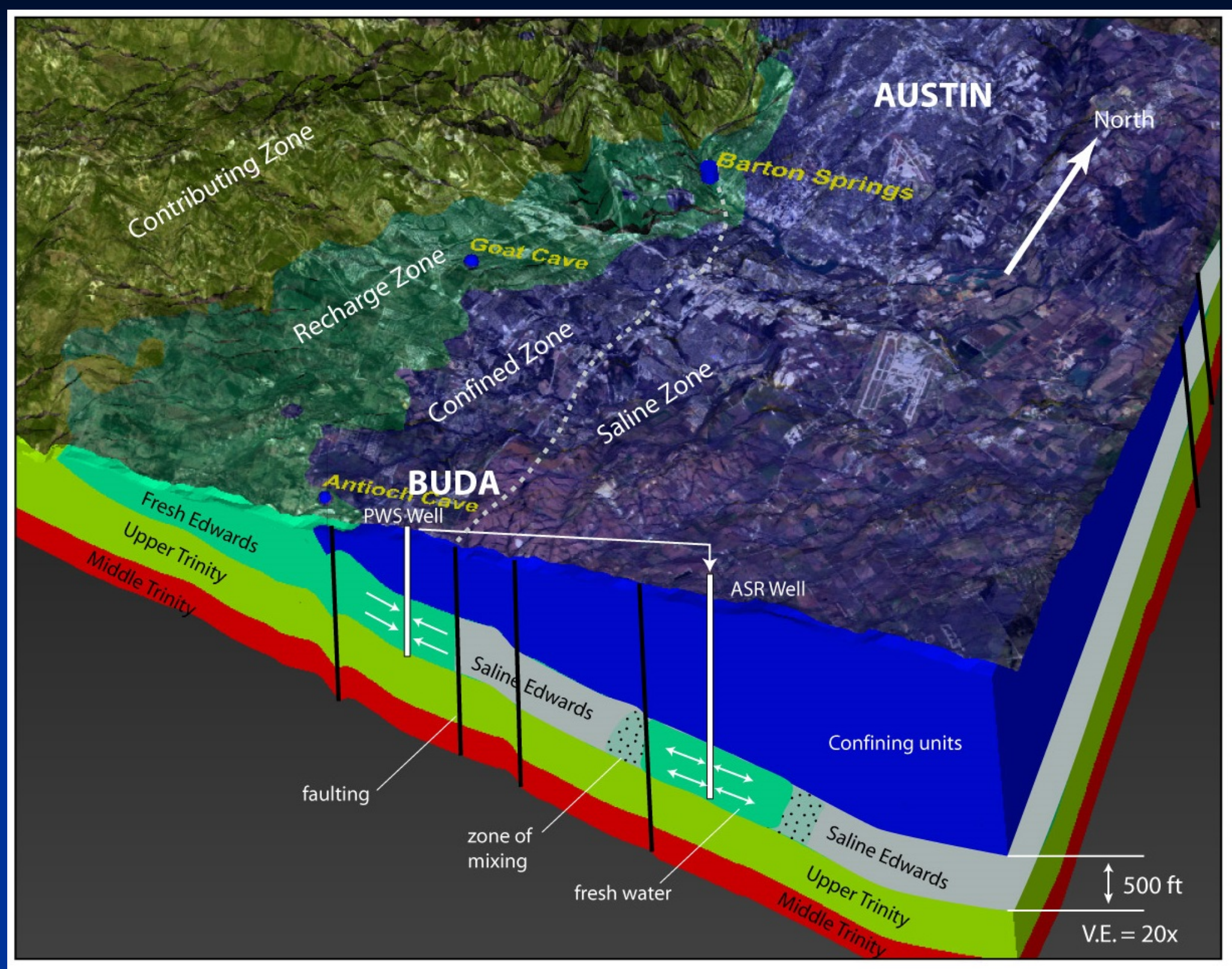

Barton Springs

Edwards Aquifer

Conservation District 


\section{TWDB Regional Facilities Planning Grant}

- Feasibility study for desalination and ASR

- Carollo Engineers

- ASR Systems (David Pyne)

- New Gen (financial analysis)

- BSEACD contribution- hydrogeologic characterization with the installation of multiport monitor well 


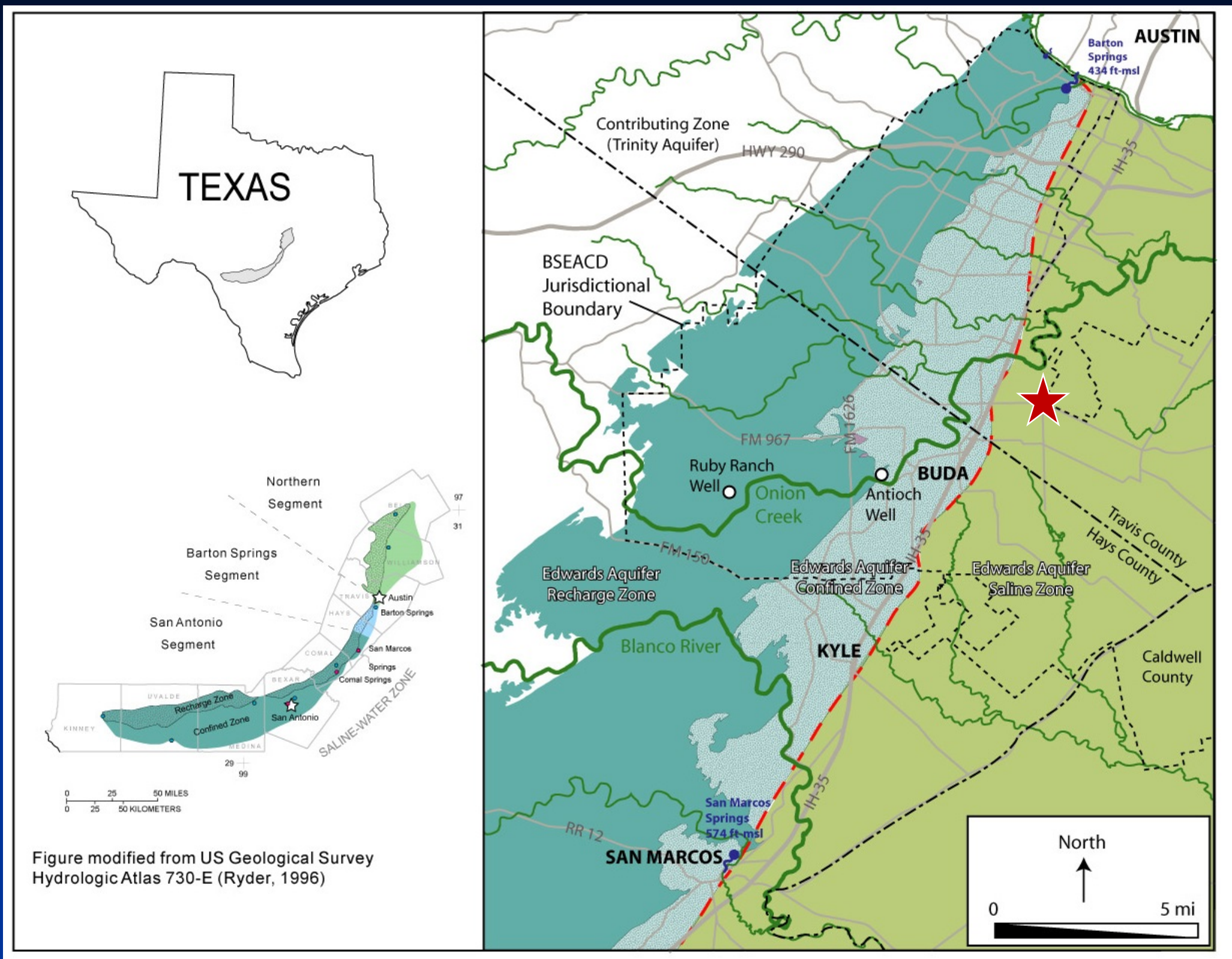

Barton Springs

Edwards Aquifer

Conservation District 


\section{Multiport Monitor Well}

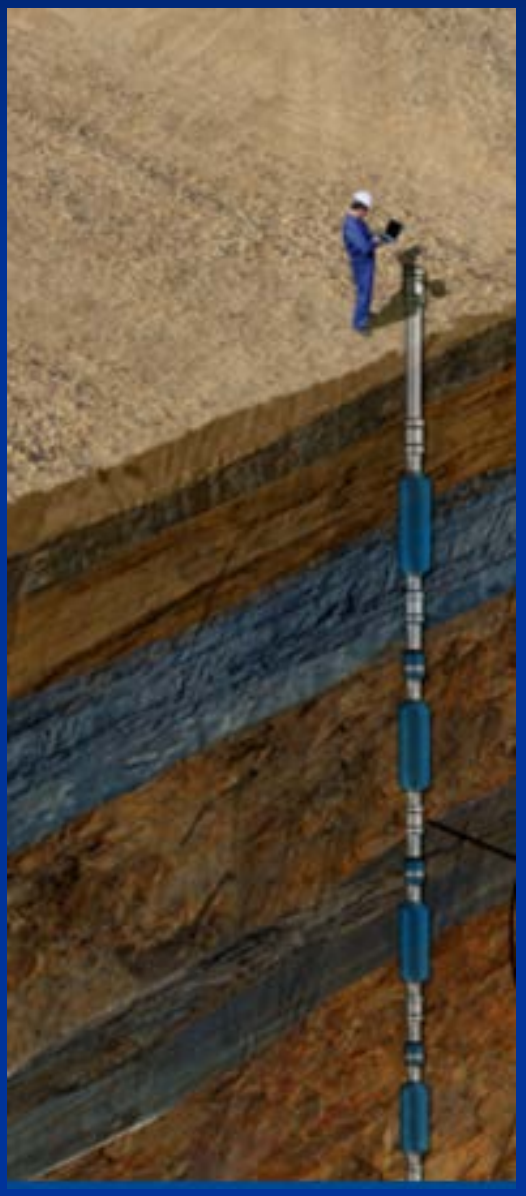

Long-term data collection:

- Fluid pressure (water levels)

- Hydraulic conductivity (slug testing)

- Sampling (geochemistry) 


\section{Drilling}
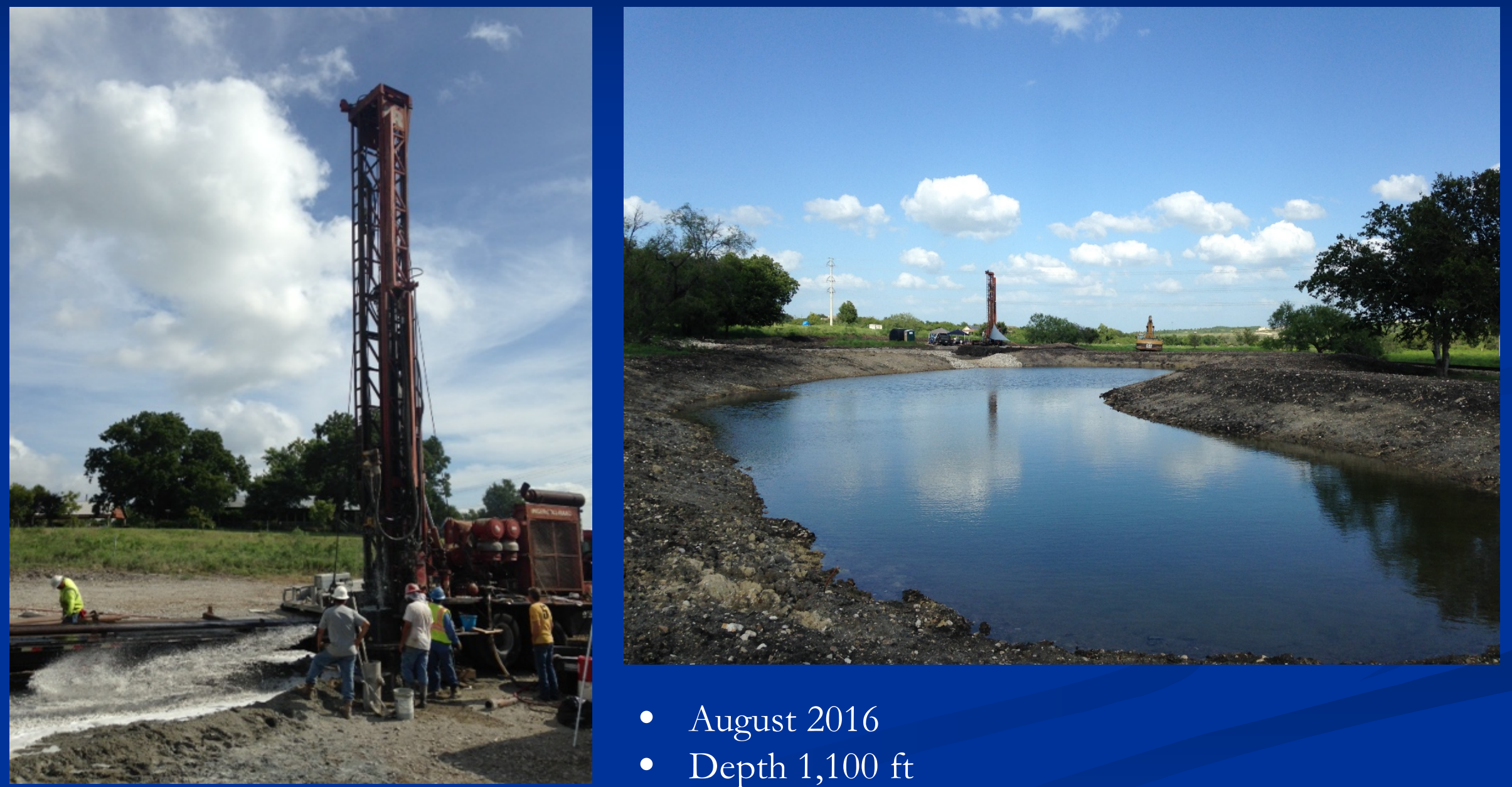

- August 2016

- Depth 1,100 ft

- Entire Edwards Group penetrated

Barton Springs

Edwards Aquifer

Conservation District 


\section{Geophysical Logging}
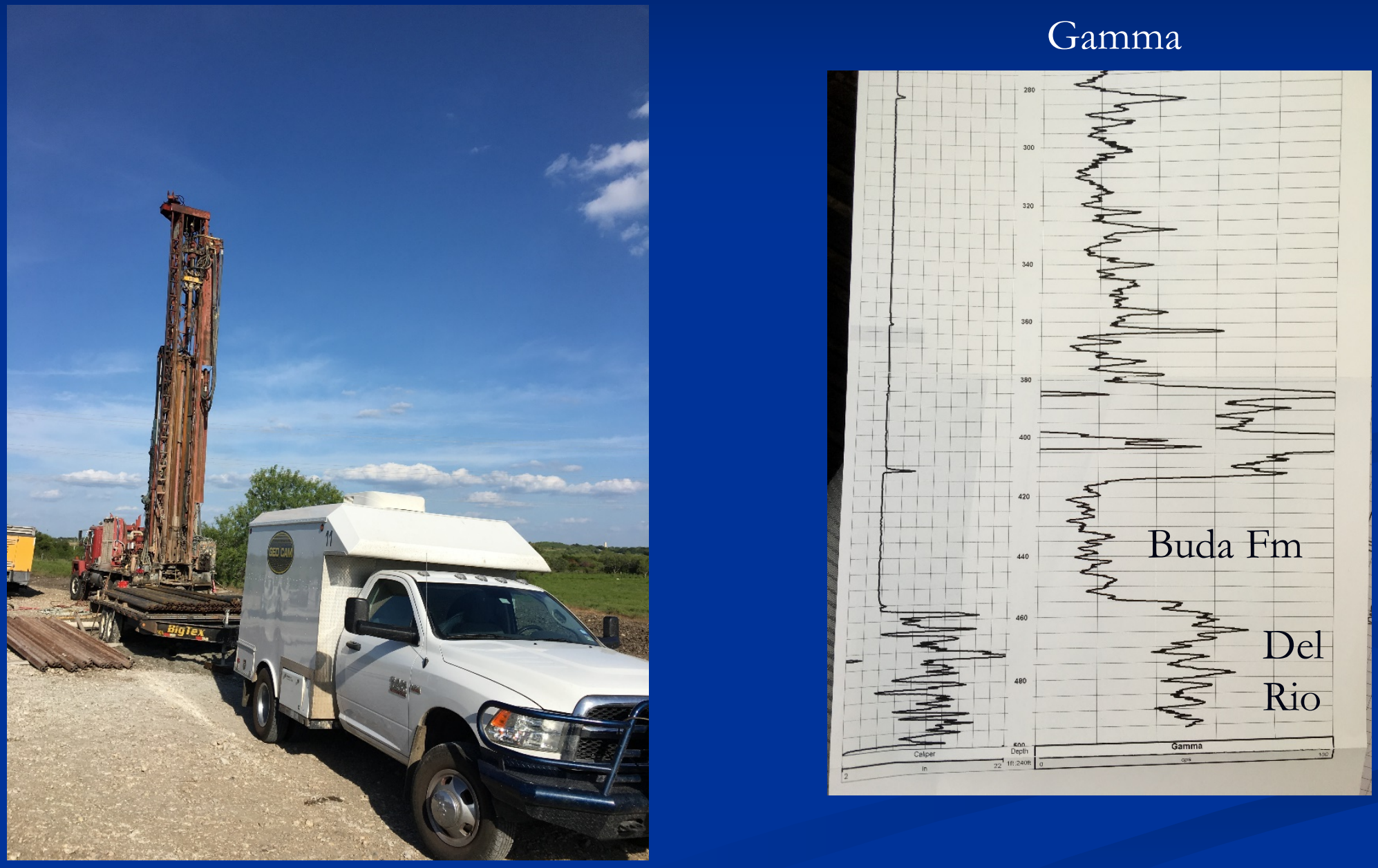

Barton Springs

Edwards Aquifer

Conservation District 


\section{Multiport Well Design}

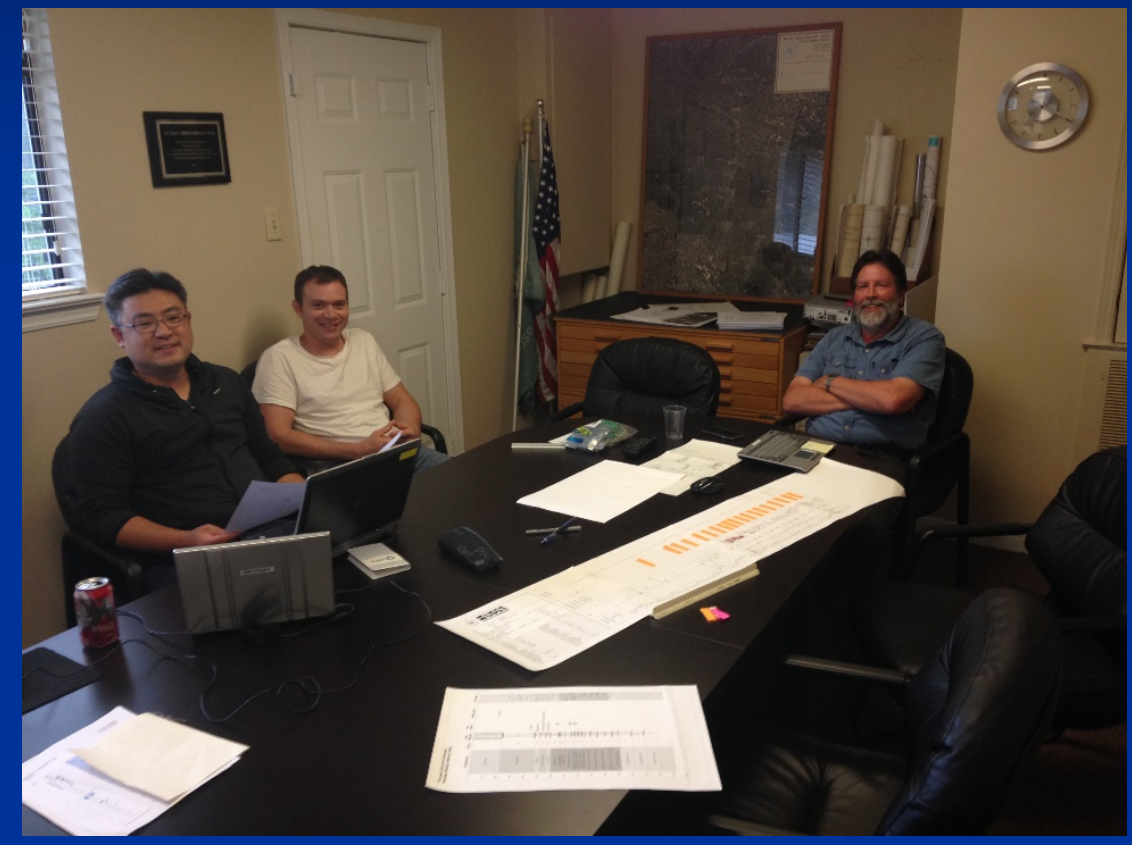

18 total zones

$>4$ confining units

$>12$ Edwards

$>2$ Upper Glen Rose

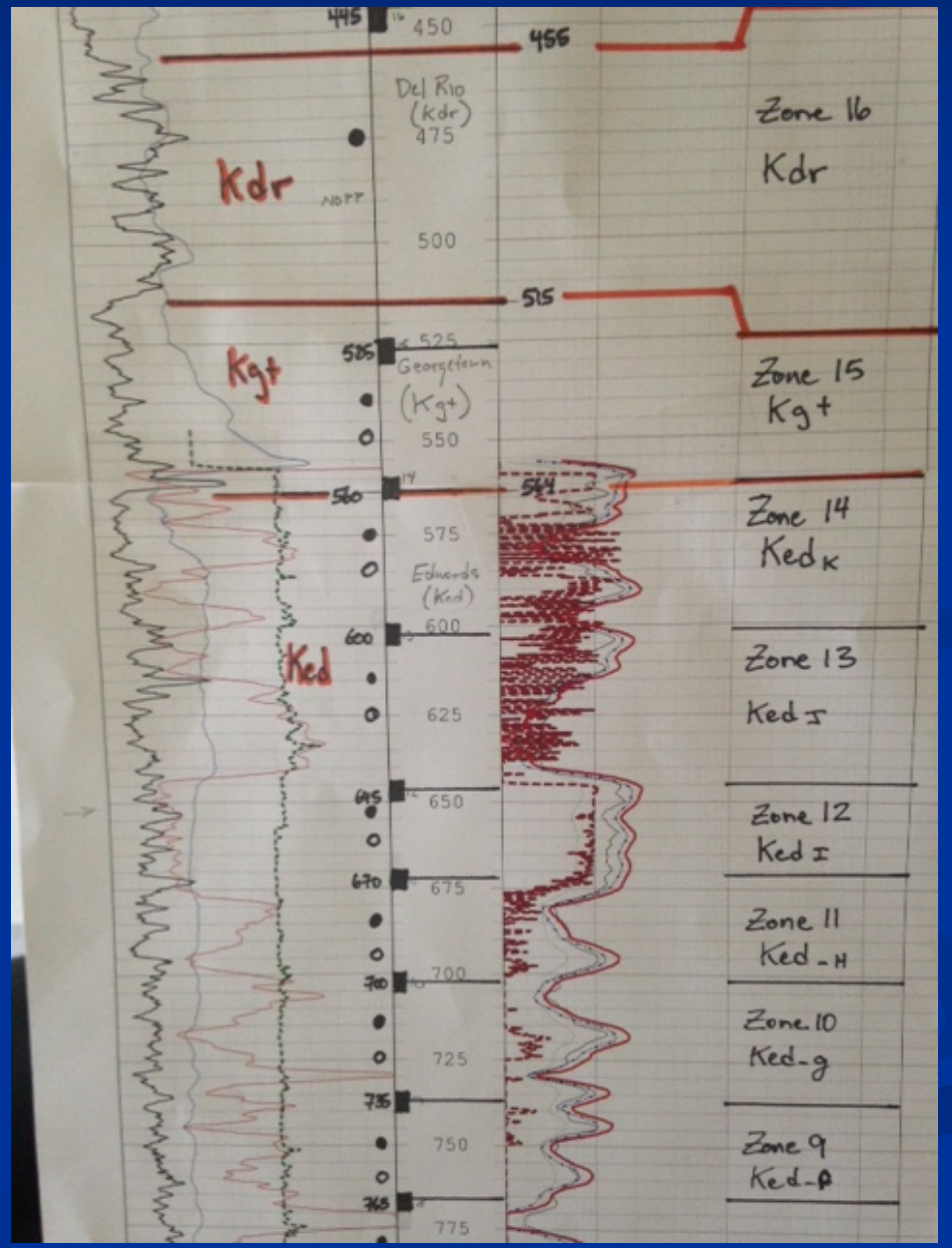




\section{Multiport Installation}
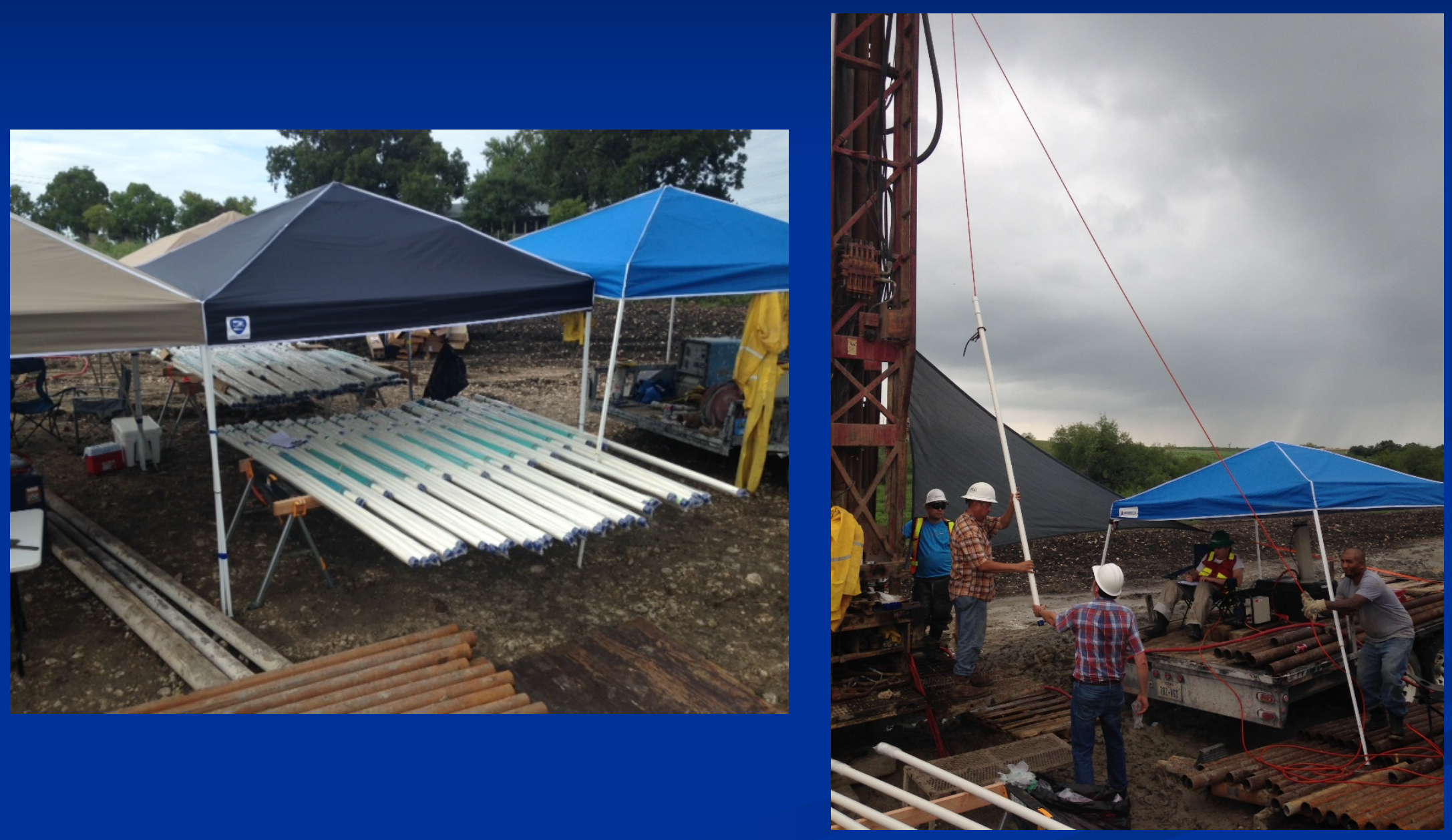

Barton Springs

Edwards Aquifer Conservation District 


\section{Multiport Installation}
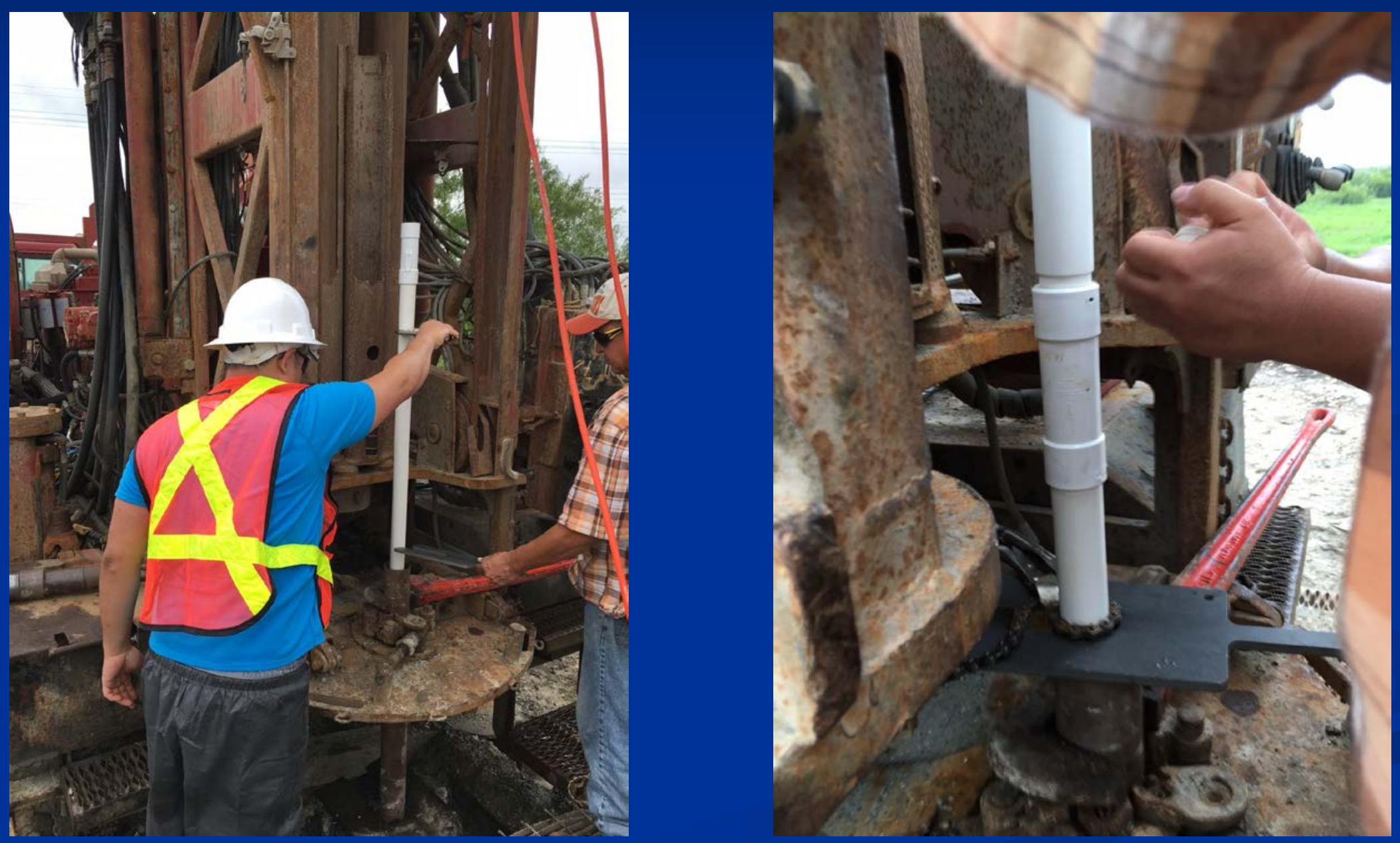

Barton Springs

Edwards Aquifer

Conservation District 


\section{Packers}
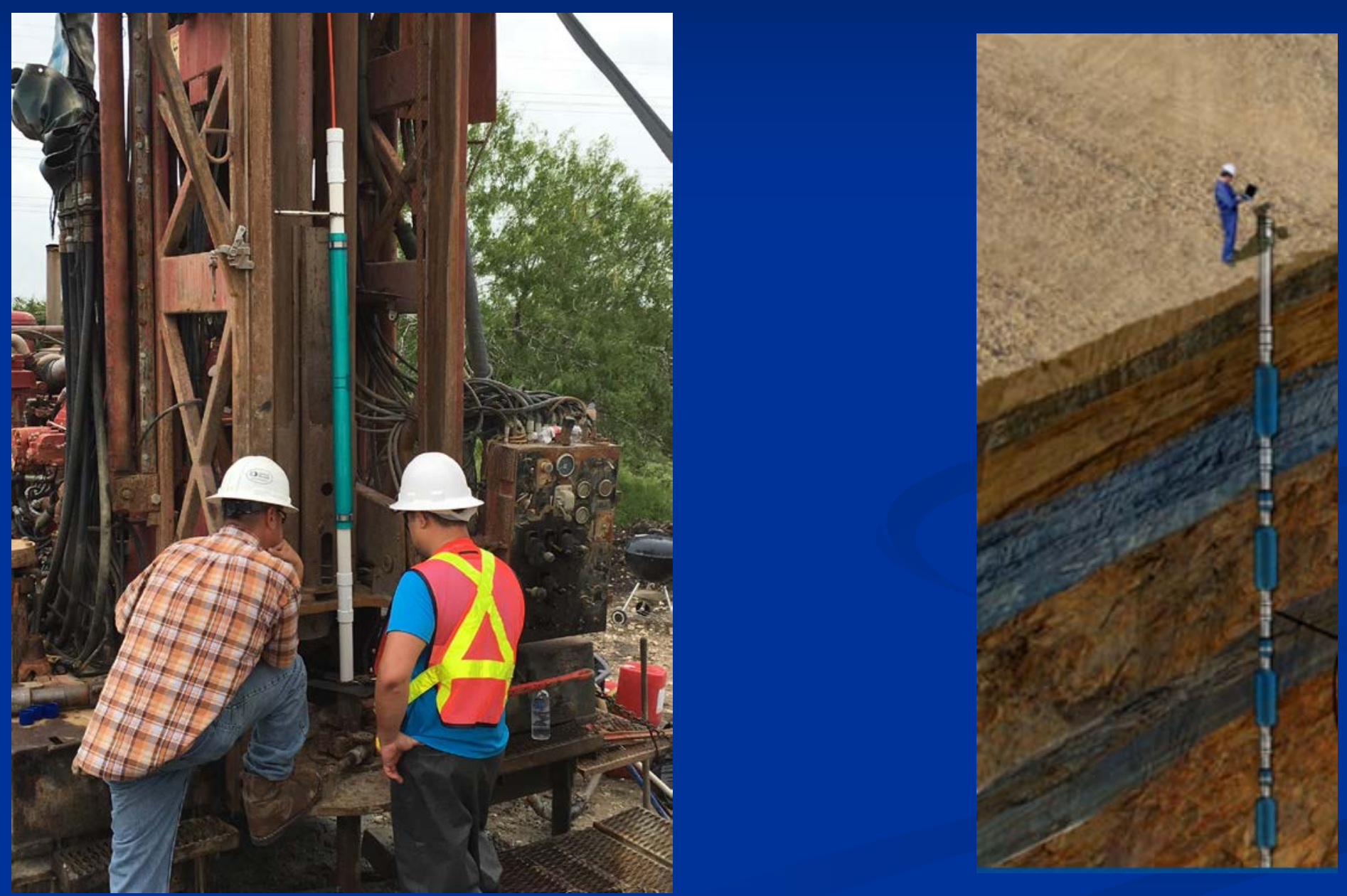

Barton Springs

Edwards Aquifer Conservation District 


\section{Purging and Slug Testing}

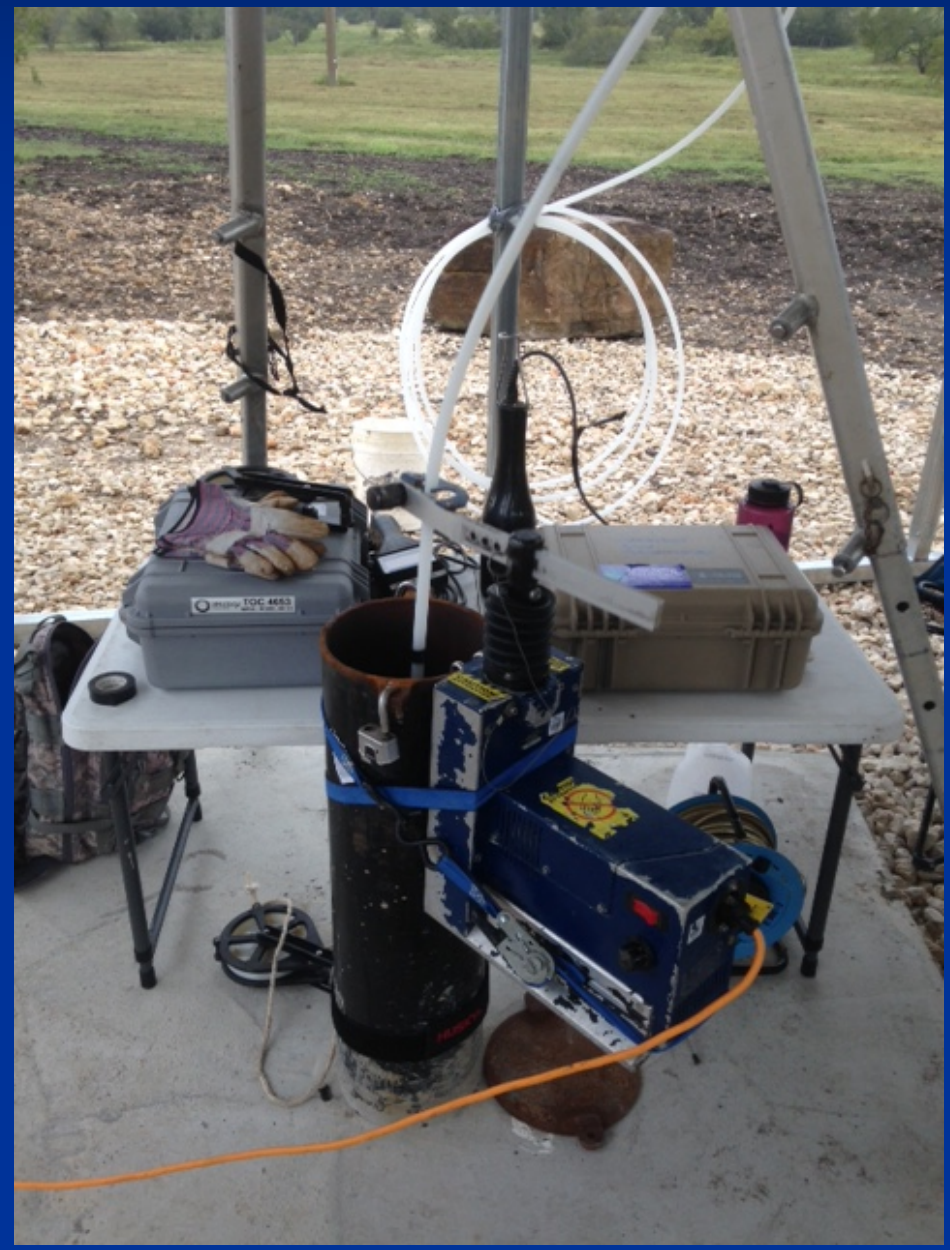

Inertial pump

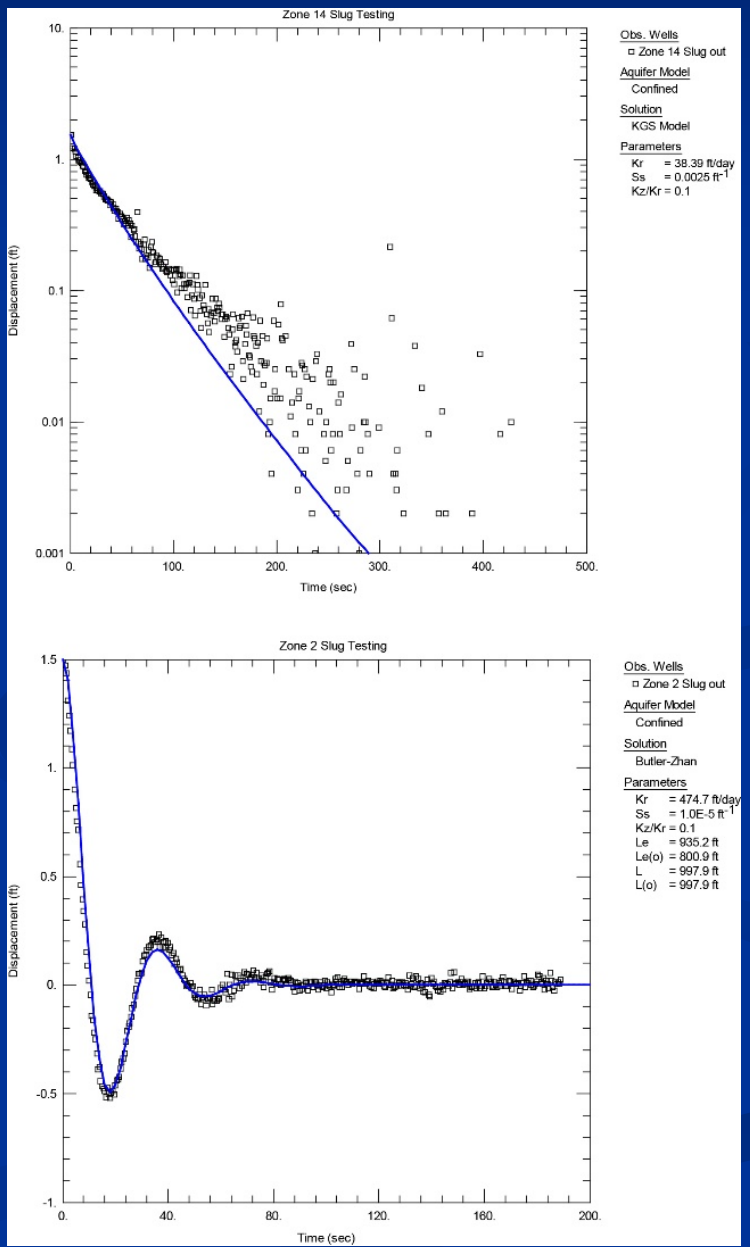

Aqtesolv 


\section{Results: Hydraulic Conductivity (ft/d)}

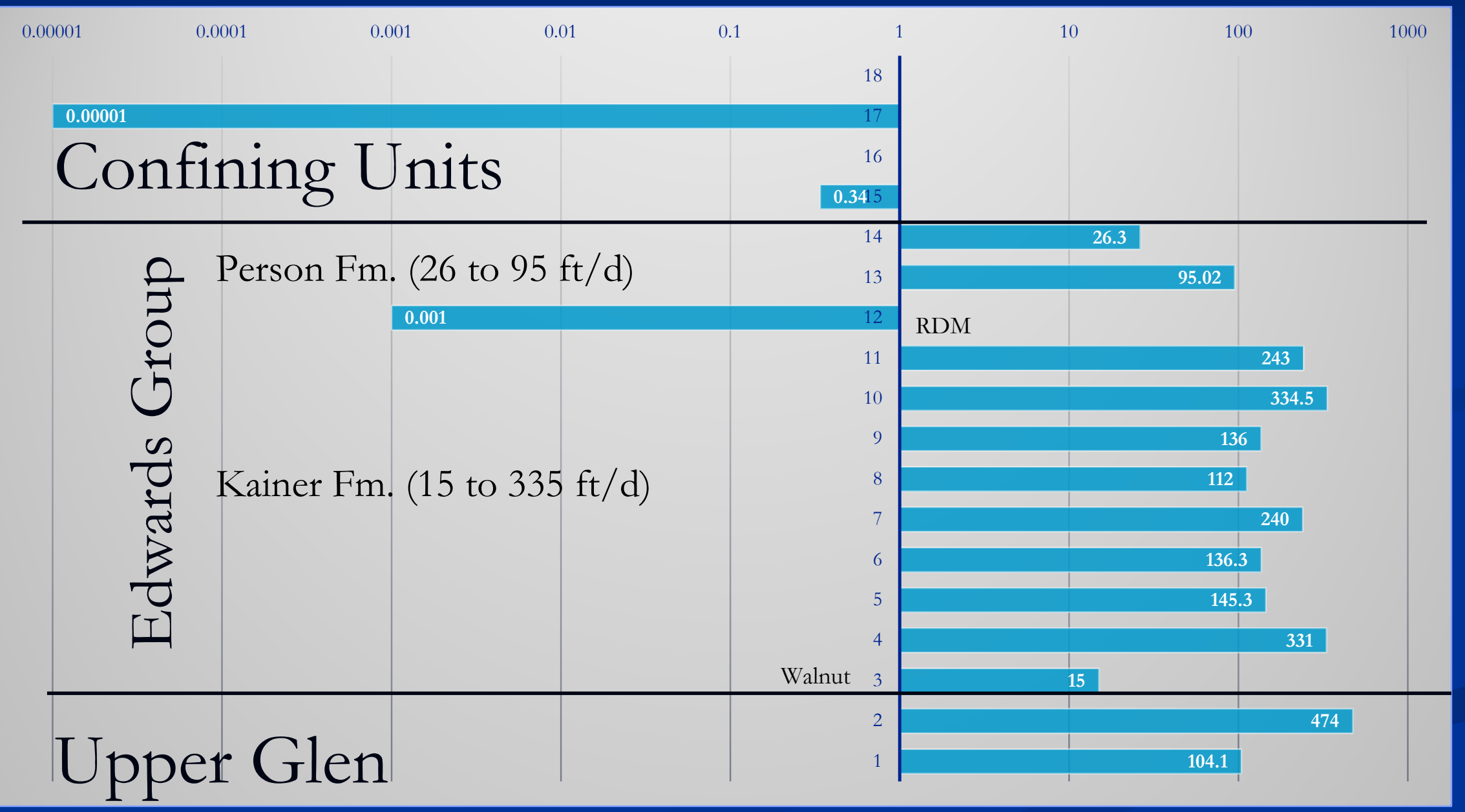




\section{Results: Heads}

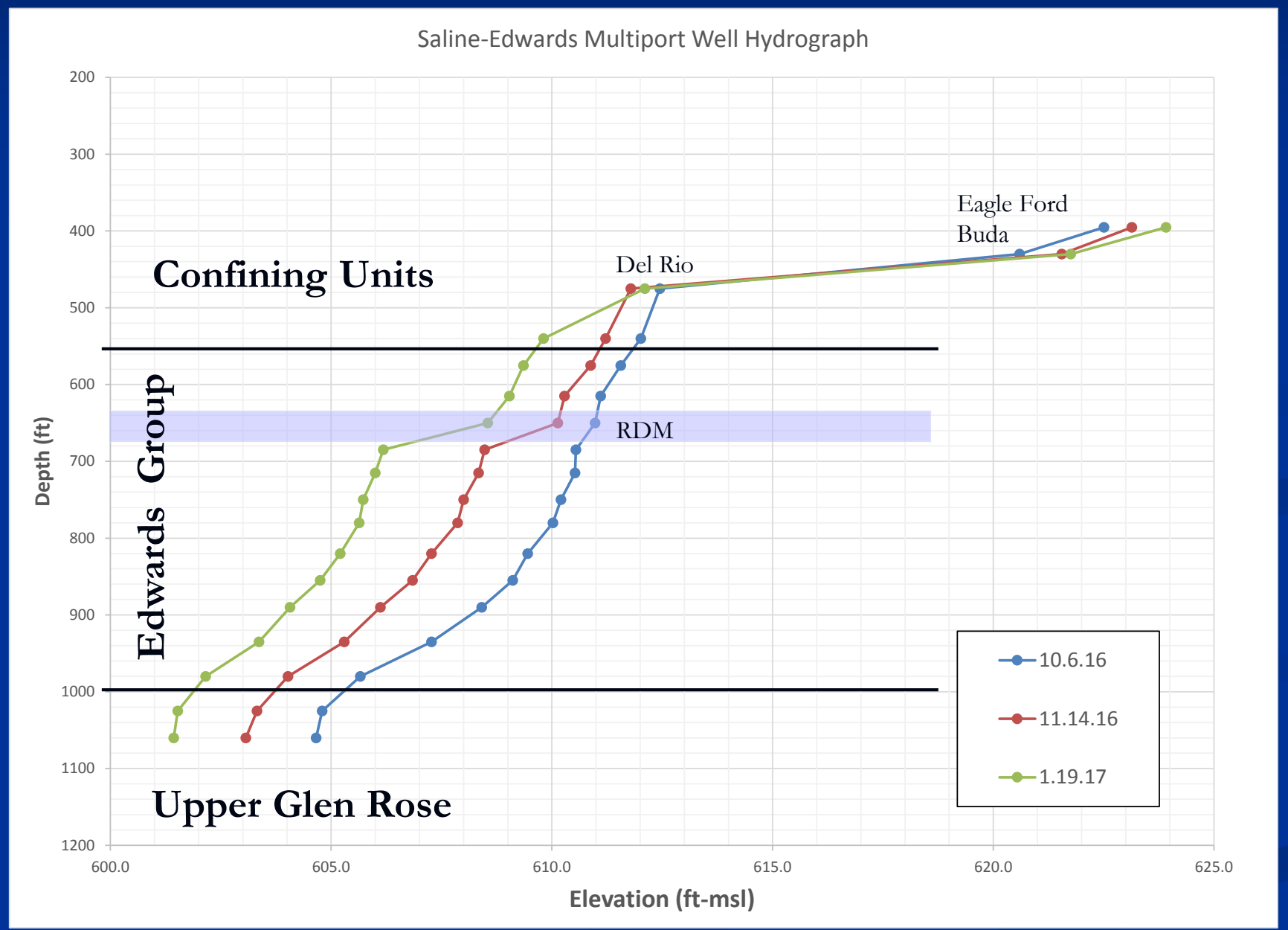

Barton Springs 


\section{Results: Geochemistry}

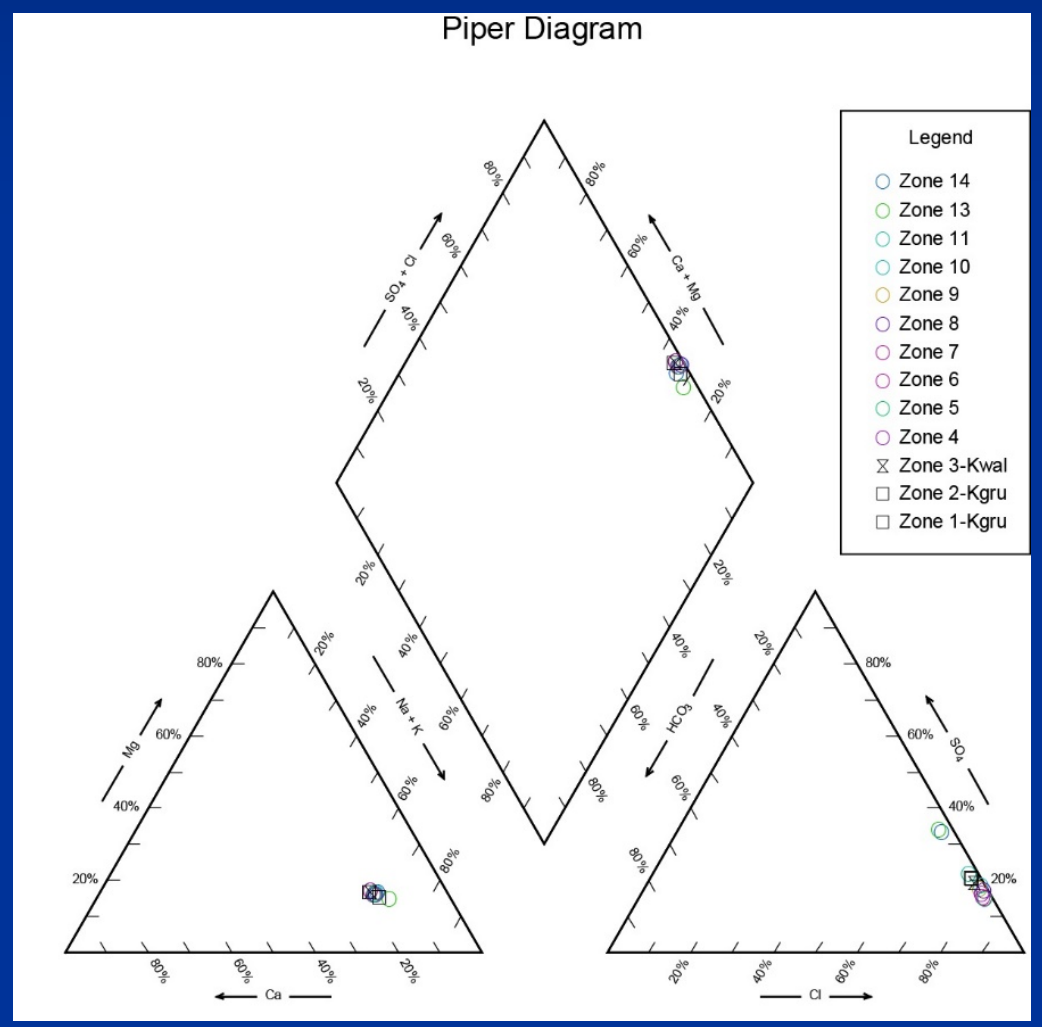

- 13 samples

- Sodium-Chloride facies

- TDS varies from

8,800 to $18,600 \mathrm{mg} / \mathrm{L}$ 


\section{Results: Geochemistry}

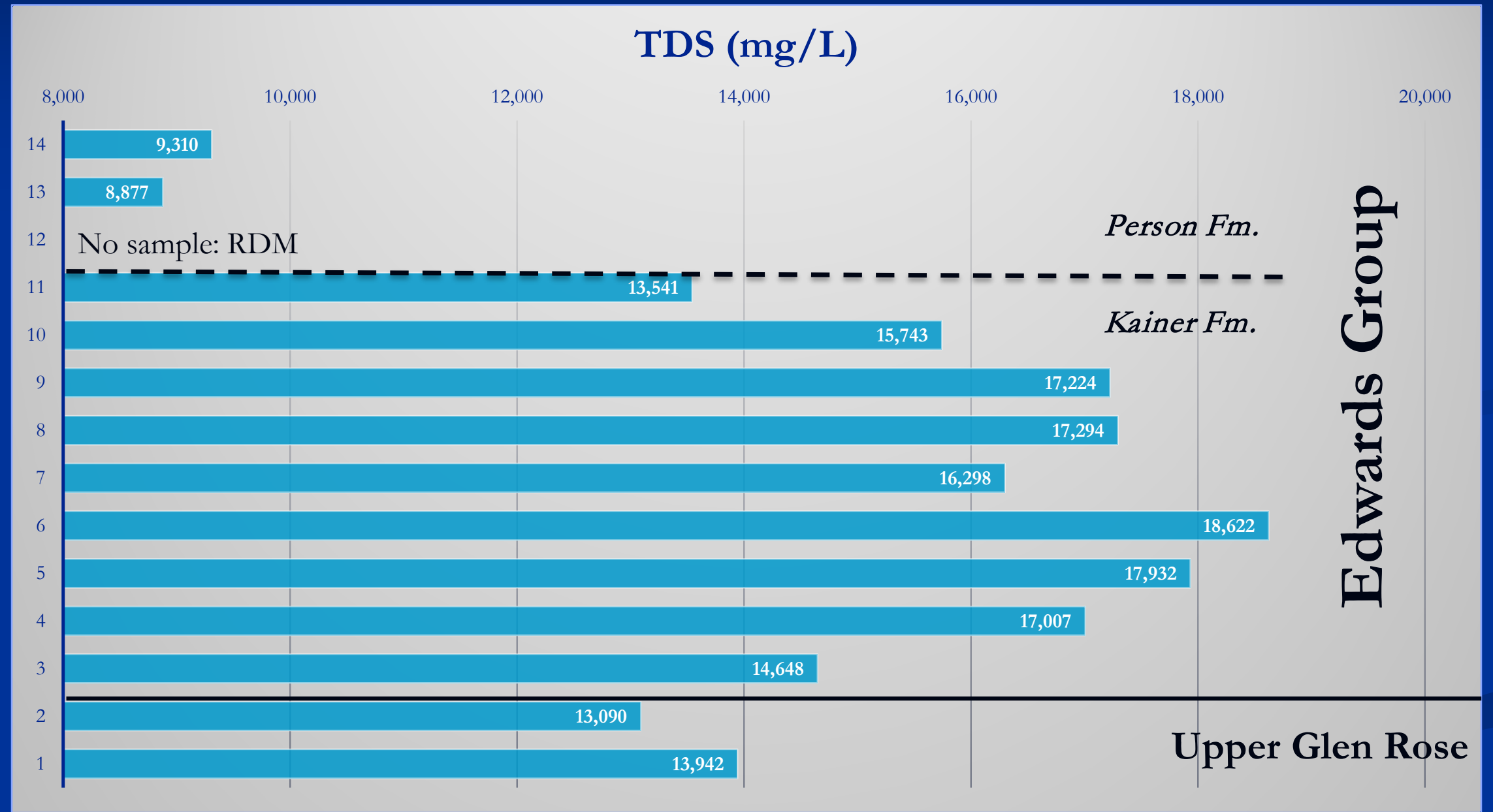

Barton Springs

Edwards Aquifer

Conservation District 
Hydrogeologic Cross Section: Fresh- to Saline-Water Edwards Aquifer

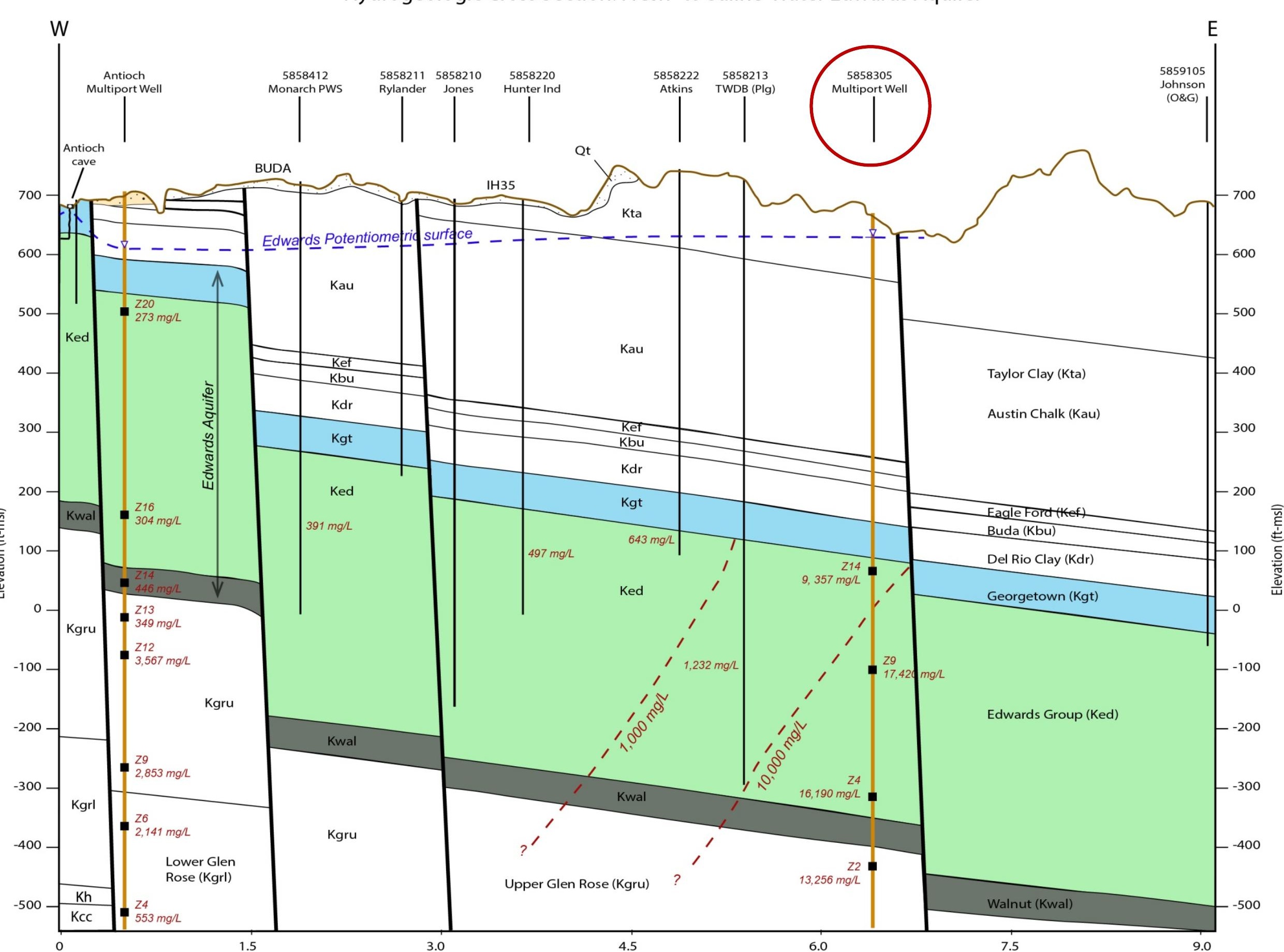




\section{Potential Well Yields?}

\begin{tabular}{|l|l|l|l|l|l|l|}
\hline Aquifer Interval & thickness (ft) & $\mathbf{T}$ avg $\left(\mathbf{f t}{ }^{\wedge} \mathbf{2} / \mathbf{d}\right)$ & Storativity & TDS (mg/L) & Drawdown (ft) & $\mathbf{Q}(\mathbf{g p m})$ \\
\hline $\begin{array}{l}\text { Upper Edwards } \\
\text { (Person) }\end{array}$ & 79 & 2,477 & 0.0002 & 9,094 & 179 & 1,300 \\
\hline $\begin{array}{l}\text { Lower Edwards } \\
\text { (Kainer) }\end{array}$ & 271 & 7,141 & 0.0002 & 16,707 & 214 & 4,300 \\
\hline
\end{tabular}

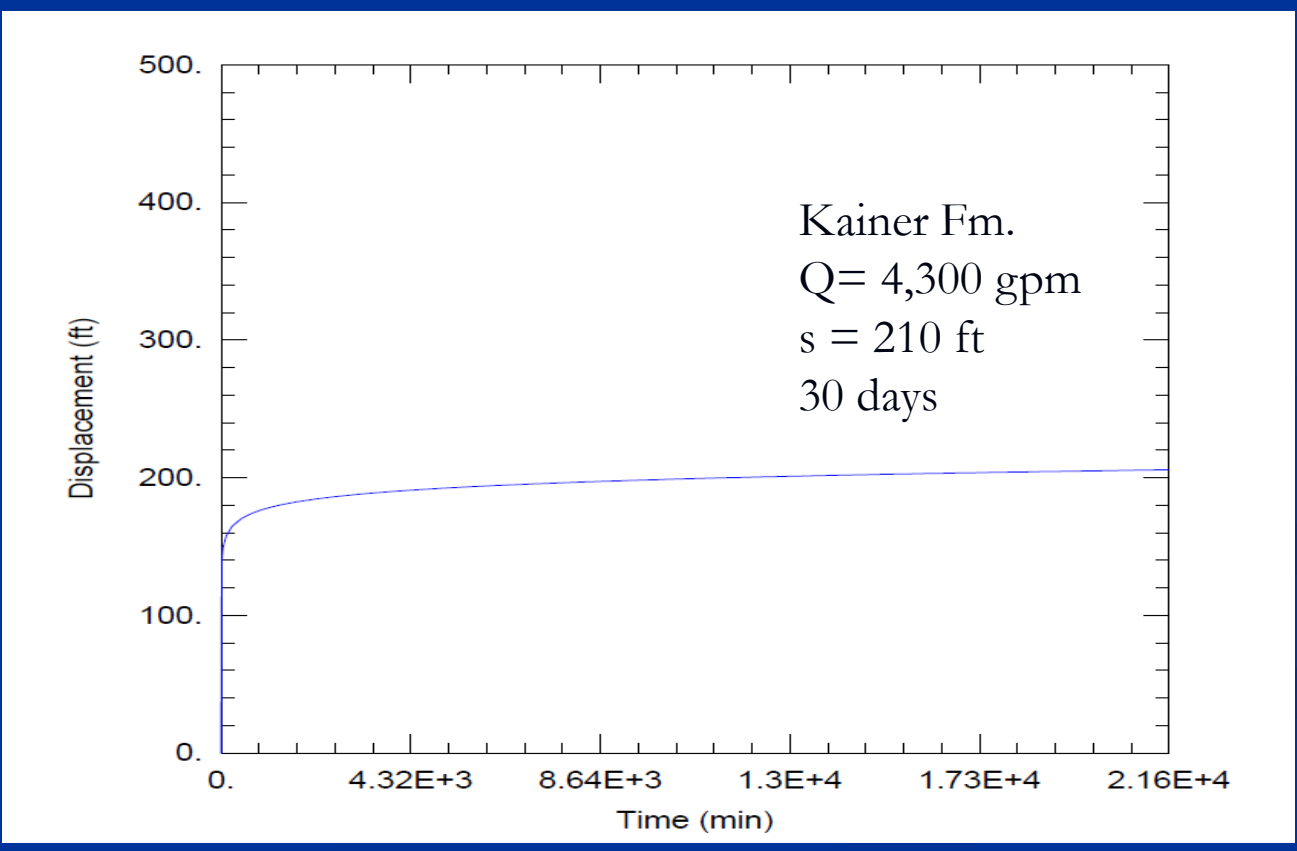




\section{Kyle Transect}

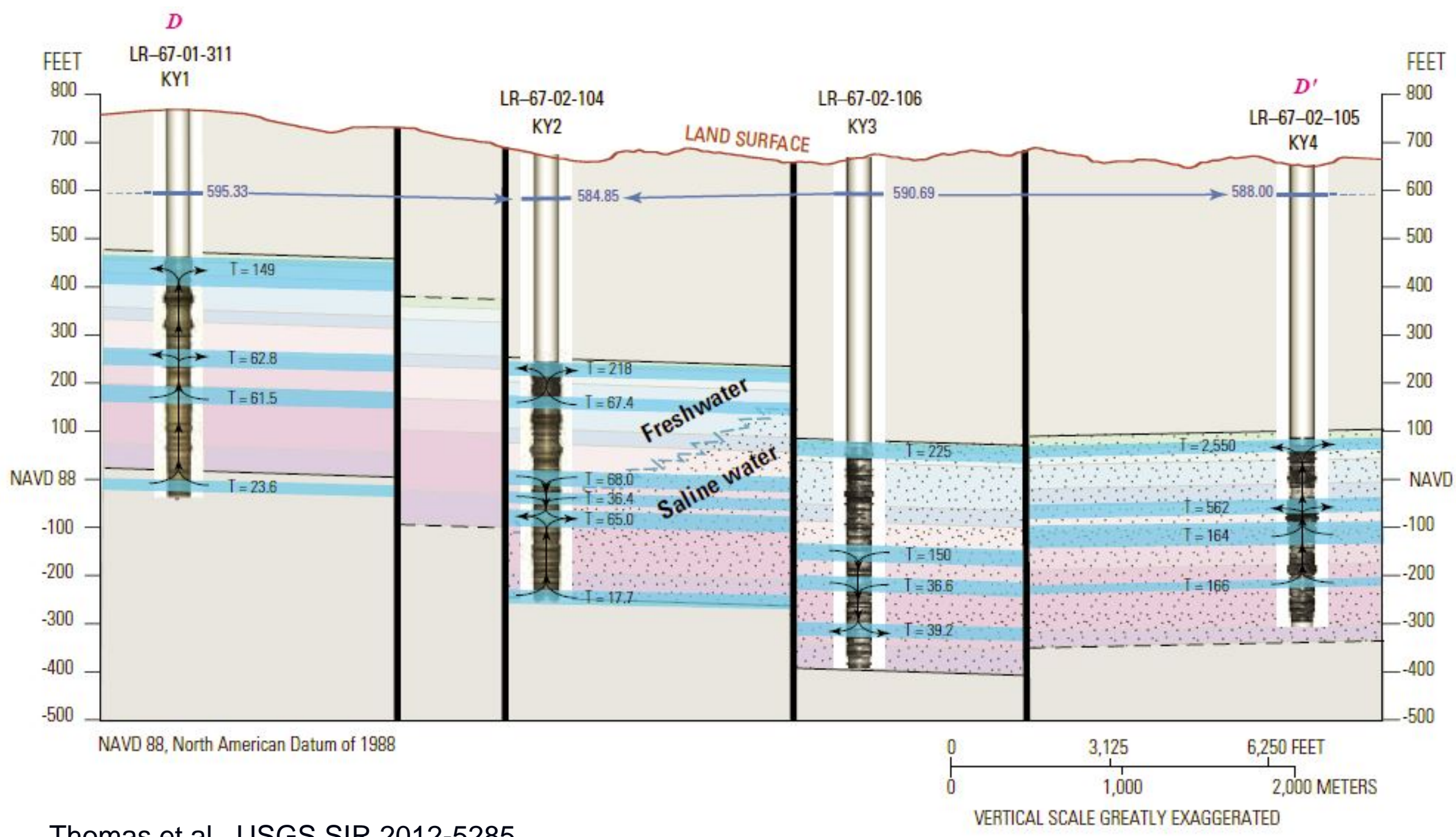

Thomas et al., USGS SIR 2012-5285 


\section{Conclusions}

- Data provide detailed data on the brackish Edwards

- TDS 9k-18k mg/L; K 0.001- 474 ft/d

- RDM appears to provide hydrogeologic stratification between Person and Kainer Fms.

- Saline Edwards/Upper Glen Rose appear very transmissive

- High-yielding wells possible 


\section{Questions?}

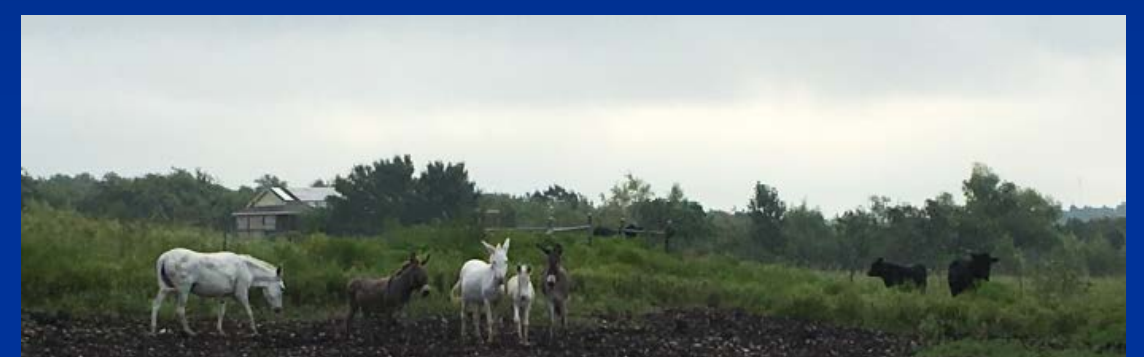

Thank you:

- TWDB

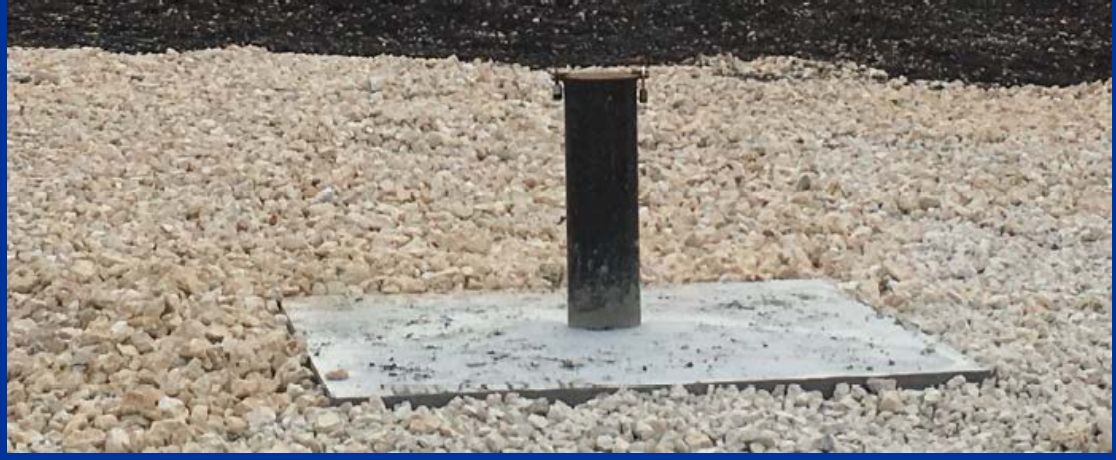

- Texas Disposal Systems 